\title{
DE MENINA A MULHER: JUVENTUDES NEGADAS POR MEIO DA EDUCAÇÃO ESCOLAR (GUARAPUAVA-1982)
}

Jorge Luiz Zaluski ${ }^{1}$

\begin{abstract}
Resumo: A educação escolar como direito foi conquistada ao longo do século $\mathrm{XX}$ e proporcionou mudanças que transcendem o conhecimento curricular. Através da investigação histórica sobre a história da educação é possível compreender noções sobre infância, juventude, família, gênero, dentre outras marcações sociais em que as propostas e práticas educacionais de contextos históricos distintos projetaram intencionalidades sobre as diferentes atividades exercidas pelas pessoas. Em finais da década de 1970, por exemplo, a obrigatoriedade da educação para o casamento e manutenção do vínculo, foi um afronte a muitos direitos adquiridos pelas mulheres. Essa proposta contribuiu para a marcação dos espaços em que homens e mulheres deveriam ocupar, formas de casar, constituir família, dentre outros. Diante disso, tendo como fonte histórica o caderno escolar de uma estudante de 15 anos, do ano de 1982 correspondente a disciplina de Indústria Caseira, pretende-se investigar parte das práticas escolares em Guarapuava-Paraná, de modo a perceber quais as noções e interesses sobre juventude da época, e de como foram reverberadas nessa educação. Deste modo, junto as investigações teóricas da interseccionalidade, busca-se perceber também as intencionalidades de outros marcadores sociais exercidas por meio dessa educação, tais como geração, gênero, condição social e classe das quais foram colocadas em prática por meio da disciplina escolar.
\end{abstract}

Palavras-chave: Educação; Juventude; Interceccionalidade; Tempo Presente.

\section{FROM GIRL TO WOMAN: YOUTH DENIED THROUGH SCHOOL EDUCATION (GUARAPUAVA-1982)}

\begin{abstract}
School education as a right was conquered throughout the twentieth century and provided changes that transcended curricular knowledge. Through historical research on the history of education it is possible to understand notions about childhood, youth, family, gender, among other social markings in which educational proposals and practices from distinct historical contexts have projected intentions about the different activities carried out by people. In the late 1970s, for example, compulsory marriage education and bonding were an affront to many rights acquired by women. This proposal contributed to the marking of spaces in which men and women should occupy, ways to marry, to form a family,

\footnotetext{
${ }^{1}$ Doutorando do Programa de Pós-Graduação em História da Universidade do Estado de Santa Catarina PPGH-UDESC. Bolsista pela Fundação de Amparo à Pesquisa e Inovação do Estado de Santa Catarina (FAPESC), Florianópolis, e-mail: jorgezaluski@hotmail.com.
} 


\section{Revista Ibero-Americana de Humanidades, Ciências e Educação \\ Produção e democratização do conhecimento na lbero-América}

among others. In view of this, having as a historical source the schoolbook of a 15-year-old student from the year 1982 corresponding to the discipline of Home Industry, we intend to investigate part of the school practices in GuarapuavaParaná, in order to perceive the notions and interests about youth of the time, and how they reverberated in that education. Thus, together with the theoretical investigations of intersectionality, it is also sought to perceive the intentionalities of other social markers exercised through this education, such as generation, gender, social status and class of which were put into practice through school discipline.

Keywords: Education; Youth; Intercectionality; Present tense.

A partir dos estudos sobre a educação é possível compreender as intencionalidades que vão para além do currículo adotado por um país, estado, município ou instituição em especifico. No que corresponde aos objetivos deste texto, os cadernos escolares permitem compreender marcações sociais sobre infância, juventude, e a vida adulta onde se visa diferentes formas de ser e agir no mundo a partir das diferenças de gênero já instituídas socialmente. Para o historiador Antonio Castillo Gómez, a escrita possui em nossa sociedade um caráter primordial para a comunicação cotidiana. Entre as mais diversas intencionalidades atribuídas à escrita, Gómez nos indica que escrevemos também para, "lutar contra a ditadura do esquecimento".(CASTILLO GÓMEZ, 2018, p. 06) Analisar a cultura escrita de determinada sociedade e tempo permite perceber parte das concepções de leitura e escrita, interesses, anseios e tensões socioculturais de um grupo onde são manifestadas por meio dos registros. Diante dessas possibilidades, e com suporte da metodologia da História do Tempo Presente (HTP), pretende-se junto à análise do caderno de uma estudante de 15 anos da qual chamo de Liza, matriculada na disciplina de "Indústria Caseira" correspondente a $7^{\text {a }}$ série C, feminina do ano de 1982, da Escola Ana Vanda Bassara, de Guarapuava - PR, investigar as propostas educacionais presentes e que foram materializadas sob a forma de escrita e que nos informam sobre as concepções sobre juventude presentes na sociedade e período observado.

Conforme Castillo Gómez, as pesquisas que buscam investigar sobre os escritos educacionais distribuem-se em diferentes eixos, sendo eles: estudá-los como dispositivos escolares; substrato ideológico; testemunho da cultura 


\section{Revista Ibero-Americana de Humanidades, Ciências e Educação \\ Produção e democratização do conhecimento na Ibero-América}

escolar; e a dimensão material dos cadernos escolares. (CASTILLO GÓMEZ, 2012) Como um exercício para parte das reflexões que irão compor a tese em desenvolvimento, pretende-se neste texto refletir sobre a produção do caderno escolar selecionado e levantar discussões que se aproximam com os eixos apresentados pelo autor. Por meio das noções conceituais sobre discurso, práticas e representações fornecidas por Castillo Gomez. Para o autor, esses três componentes integram a produção da escrita e são fundamentais para perceber as intencionalidades da produção e de como os aspectos da sociedade integram materializam-se pela escrita. (CASTILLO GÓMEZ, 2018)

Pretende-se também neste texto promover uma análise interseccional. Adriana Piscitelli nos informa que as abordagens que se utilizam da intersecção vão além da categoria gênero. Para a autora, existiu uma "centralidade concedida ao gênero em termos das forças sociais que oprimem às pessoas." (PISCITELLI, 2008, p. 264) Logo, marcadores como etnia, classe, geração, dentre outros, são pertinentes para a investigação histórica que parte da interseccionalidade. Conforme Piscitelli, "A proposta de trabalho com essas categorias é oferecer ferramentas analíticas para apreender a articulação de múltiplas diferenças e desigualdades." (PISCITELLI, 2008, p. 266). Para tanto, a articulação proposta pela autora torna possível compreender as concepções sobre juventude, homens, mulheres, etnia, condição social, dentre outras, reverberadas por meio da disciplina de "Indústria Caseira". Em um sentido amplo, perceber as possíveis interações.

\section{Tensões sociais e as escritas escolares}

Conforme o historiador François Dosse, o acontecimento deve ser compreendido, "[...] como resultado e como começo, como desfecho e como abertura de possíveis." (DOSSE, 2013, p. 06) Ou seja, a pesquisa histórica deve ater-se ao desenvolvimento, realização e os efeitos do acontecimento. Uma história em movimento, que como destaca Dosse, "[...] poucos são os acontecimentos sobre os quais podemos afirmar que terminaram porque estão ainda suscetíveis de novas atuações."(DOSSE, 2013, p. 07) 


\section{Revista Ibero-Americana de Humanidades, Ciências e Educação \\ Produção e democratização do conhecimento na Ibero-América}

Durante a década de 1970, muitas tensões sociais existentes geraram diferentes acontecimentos onde seus efeitos passaram a agir e provocar novas atuações ao longo do tempo. A Lei de Diretrizes e Bases da Educação (LDB) №. 5.692 de 11 de agosto de 1971, por exemplo, tornou obrigatório que todas as escolas do país ofertassem o ensino pautado para a formação técnica. Para o ensino fundamental II de $5^{\underline{a}}$ a $8^{\underline{a}}$ séries, a instrução deveria ser direcionada como introdutória para o desenvolvimento das aptidões. Já no ensino médio, a instrução técnica deveria ser estreitamente relacionada a uma profissão em específico conforme as necessidades de cada localidade.

Para além do espaço escolar, conforme Claudia Regina Nichning, Marlene de Fáveri e Teresa Adami Tanaka, ao investigarem sobre algumas das conquistas das mulheres adquiridas durante a década de 1970, as autoras afirmam que existiu uma forte pressão por parte da sociedade contrária a aquisição de direitos para as mulheres em relação à separação. (NICHINING, 2013; FÁVERI; TANAKA, 2010). Nesse cenário pautado na profissionalização e busca por parte da sociedade contrária a "Lei do Divórcio" conquistado em 1977, em 18 de junho de 1979, o Decreto-Lei 6.660 integrou também a obrigação das instituições de ensino para ofertar "a preparação para o casamento e a preservação do vínculo que o constitui." (BRASIL, 1979) Esse decreto age como um efeito, tal como nos informa Dosse. Logo, esse acontecimento continua provocando novas configurações a medida que seus efeitos propagam-se sobre os sujeitos.

Diante das novas exigências para com o ensino, essa decisão fez com que os currículos e práticas escolares fossem organizados para atender a legislação. A disciplina de "Indústria Caseira", por exemplo, ofertada na Escola Ana Vanda Bassara em Guarapuava-PR corresponde a uma das alternativas para preparar para o casamento e manutenção do vínculo. Projeções construídas com base na experiência em modelos educacionais anteriores, onde por meio da Lei Orgânica do Ensino Secundário de 1942, meninas/mulheres deveriam receber a educação diferente da dos meninos/homens. Como forma de lei perdurou a obrigatoriedade desse ensino até a promulgação da primeira LDB 


\section{Revista Ibero-Americana de Humanidades, Ciências e Educação \\ Produção e democratização do conhecimento na Ibero-América}

(1961) que extinguiu tais medidas. Contudo, por meio dessa releitura para atender uma educação para o casamento, novos reforços de desigualdades de gênero, etnia, classe, dentre outras distinções e exclusões sociais passaram a serem reforçadas. Conforme Reinhart Koselleck, "todo ato histórico se realiza com base na experiência e na expectativa dos agentes." (KOSELLECK, 2014, 307) Logo, as propostas educacionais pós 1977 manifestam-se como efeitos dos acontecimentos, nas experiências obtidas por meio de modelos educacionais anteriores e na atribuição de um horizonte de expectativa pautado em delimitar espaços, atribuições e construir novas relações sociais.

O caderno produzido pela estudante possui o conteúdo dividido em duas partes. Na primeira, trata sobre etapas do casamento, sendo eles: construção da casa; namoro; noivado; casamento civil e religioso; lista de utensílios e roupas necessários para casar. $\mathrm{Na}$ segunda, corresponde sobre a realização de atividades para casa e corpo, sendo eles; orçamento doméstico; limpeza; preparo de alimentos; cuidado com os/as filhos/as; costura. Em relação ao corpo, limpeza de pele, maquiagem e cuidado com os cabelos e unhas.

Ao registrar em seu caderno, "Onde está o príncipe encantado? É a pergunta que toda jovem faz a si mesmo quando começa a pensar oficialmente no casamento." (INDÚSTIA CASEIRA, 1982, p. 07) E, ao apontar as definições sobre o rosto como "pele normal livre de espinhas, cedosa, com ligeira coloração e textura em forma de pele de pêssego." (INDUSTRIA CASEIRA, 1982, p.43) Nos permite perceber que a disciplina mencionada desenvolveu um ensino pautado nas concepções heteronormativas onde a juventude é marcada para o gênero feminino como um período para pensar sobre o casamento. Em que por meio do ensino proferido o mito do amor romântico é uma das formas utilizadas para instruir as estudantes de seguir o matrimonio. Já no que corresponde à associação da pele ao pêssego, demostra uma prática racista, pois associa a definição de pele branca como a ideal e contribui para reforçar estereótipos já instituídos socialmente onde o corpo negro é julgado e inferiorizado.

Esses enunciados permitem também perceber os interesses em delimitar o desenvolvimento geracional das estudantes. Atribuições construídas em torno 


\title{
Revista Ibero-Americana de Humanidades, Ciências e Educação \\ Produção e democratização do conhecimento na Ibero-América
}

de marcações corporais e dos significados culturais atribuídos ao corpo. Luís Antonio Groppo, nos informa que ciência, Estado e instituições sociais, contribuem para demarcar 0 as concepções de juventude vigentes em cada época. (GROPPO, 2017) Com as análises ainda em desenvolvimento, e no que compete às limitações deste trabalho, propõe-se aprofundar a discussão sobre parte da segunda etapa dos manuscritos existentes no caderno.

Desta maneira, como parte do conteúdo da disciplina. Liza registrou que:

\begin{abstract}
Como deve concorrer a mulher para um mundo melhor?
R: Dá [sic] ação feminina isto é da atuação da dona de casa, a influência da mulher é gerente do lar, pode depender o bem da sociedade em geral, pois o caráter da criança é formado nos joelhos da mãe, a qual fornece a sociedade de cidadão perfeitamente capazes de promover 0 progresso e a felicidade pois necessitam de apoio desde jovem.( IDÚSTRIA CASEIRA, 1982, p.62)
\end{abstract}

Como parte do conteúdo educacional, os manuscritos permitem perceber o interesse em projetar o futuro das estudantes. Um horizonte de expectativa em que as meninas são vistas como futuras mulheres onde a maternidade é colocada como natural. Representadas como gerentes e capacitadas para a atuação dentro de casa, os ensinamentos, colocados em prática, refletiriam na sociedade em geral. Como explícito na resposta da pergunta: para o mundo, não apenas para o lar. Mesmo com todo esse reconhecimento e importância atribuída à atuação de gerência, as mulheres são apresentadas como mães: são elas que devem ser as responsáveis por criar os/as filhos, atuantes em busca do dito progresso.

César Castro e Coelho e Vera Lucia Puga, ao analisarem o Código Cível de 1916, nos informam a existência de uma extensa e insistente legislação que priorizou reforçar as desigualdades entre homens e mulheres onde atribui-se aos homens prestigio, liberdade e poder sobre as mulheres. Ao comparar os manuscritos do caderno e a legislação ainda vigente no período, é possível perceber que essa educação foi desenvolvida sob os preceitos do código escrito no início do século XX. Segundo os autores, diante dessa lei "A interpretação 


\section{Revista Ibero-Americana de Humanidades, Ciências e Educação \\ Produção e democratização do conhecimento na Ibero-América}

corrente na jurisprudência era de que a mulher deveria cumprir com seu papel social de mãe dedicada aos filhos e esposa fiel, somente assim seria possível criar uma sociedade civilizada e trabalhadora." (COELHO; PUGA, 2009, p.18)

Diante dessa observação, é possível destacar que a disciplina de Indústria Caseira, mesmo tendo ressignificado de forma sutil como deveriam ser as mulheres, contém em seus enunciados um reforço das diferenças de gênero, onde reforça-se também outras diferenças como as de geração e etnia, e incide sobre a composição cultural e jurídica aceita no período. Sustentado por um patamar racional e moderno: valoriza a atuação das mulheres em um espaço doméstico reformulado, em um período em que todo o país estava envolto no discurso de modernização. Desenvolvimento tão esperado que se constituiria na medida em que os filhos (masculino) destas mulheres - esposas e mães -, saíssem de casa gradativamente para promover tal ação. Logo, além de encarregadas na criação de uma nova geração, realizariam tal tarefa de maneira a reproduzir as diferenças e desigualdades entre homens e mulheres. Destacase ainda que a educação dessa disciplina ao informar que são filhos que irão promover o progresso, informa que a juventude das estudantes está para o casamento, maternidade e o lar. Já as concepções de juventude para o gênero masculino informam como jovens ativos e produtivos com acesso aos diferentes espaços da vida pública. E em meio a essas relações desiguais, como secundárias nas ações e atividades dos homens, essa hierarquia é passada aos filhos. Como nos indica Coelho e Puga, imersos nessas relações socioculturais, "o homem incorpora para si todas as qualidades que a sociedade julga necessárias, como: ser racional, trabalhador, honesto, honrado, provedor, entre outros, de uma forma às vezes consciente ou não." (COELHO, PUGA, 2009, p. 16)

Desta maneira, tanto a proposta da legislação educacional, as relações com o Código Cível de 1916 e as reverberações dessas leis materializadas nos escritos de Liza, permitem perceber a insistência do passado em um período onde as mulheres já haviam conquistados muitos direitos. Uma movimentação extensiva onde o passado ainda apresenta sentido na constituição do presente. 


\section{Revista Ibero-Americana de Humanidades, Ciências e Educação \\ Produção e democratização do conhecimento na Ibero-América}

Tal como nos aponta Dosse, "a história do tempo presente está na intersecção do presente e da longa duração. Esta coloca o problema de se saber como o presente é constituído no tempo." (DOSSE, 2012, p. 06)

Para Roger Chartier, as produções manuscritas permitem compreender quais as relações estabelecidas com a cultura escrita. No que compete para este trabalho, cabe destacar que a transmissão dos ensinamentos existentes no caderno escolar corresponde a expectativas compartilhadas por parte da sociedade. Em um período de ascensão das mulheres e busca por novos direitos e garantias sociais, essa proposta educacional permite perceber que para além de interesses pautados na composição do currículo, existiu um reforço jurídico sobre as concepções de homens, mulheres, infância, juventude e família. Em meio à ação pedagógica demostrada, a escola age como autorizada a legitimar as desigualdades e demais interesses projetados. Tal como destaca Chartier, servem-se como "mecanismos que fazem os dominados interiorizarem sua própria inferioridade ou ilegitimidade." (CHARTIER, 2010, p. 47)

Ainda em relação a organização social, Castillo Gómez nos informa que a cultura escrita permite regular a sociedade. Para além do domínio da leitura e da escrita, onde se manifestam sistemas de afirmação e exclusões dos grupos sociais, a escrita pode ser compreendida como um discurso que normatiza. Para o autor, "o discurso implica umas pautas de funcionamento onde estão traçadas suas próprias contenções e exclusões, o que se aceita e o que se rejeita, as pessoas admitidas e as excluídas."(CASTILLO GÓMEZ, 2018, 40) Junto ao discurso, a prática é outro elemento fundamental, pois é em meio ao exercício da escrita que marca a posição do/a escritor/a e o domínio ou não das normas, regras, grafia e demais domínios necessários para a escrita. Assim, junto ao discurso e prática existe a representação, onde por meio do texto busca-se tornar inteligível aquilo que não se faz presente. Conforme Castillo Gómez, a representação "supõe mostrar algo ou fazer presente uma ausência e exibir a própria presença como imagem, isto é, apresentar-se representando algo que se constitui como tal quando há um sujeito que olha (ou que lê)." (CASTILLO GÓMEZ, 2018, p. 43) 


\section{Revista Ibero-Americana de Humanidades, Ciências e Educação \\ Produção e democratização do conhecimento na lbero-América}

Desta maneira, por meio de uma ação legítima, a educação proporcionada na escola e materializada na produção dos manuscritos do caderno da estudante demostra o interesse em dar continuidade as relações sociais pautadas nas diferenças entre homens e mulheres, geração, etnia, dentre outras marcações já instituídas socialmente. As mulheres, idealizadas pela disciplina Indústria Caseira, deveriam ser jovens, esposas, mães produtivas, higienizadas e racionais. Assim, como um discurso regulador, a prática da escrita de Liza permite construir um horizonte de expectativas para sua vida adulta pautada no modelo de mulher representada nos manuscritos. Ainda nos registros de Liza:
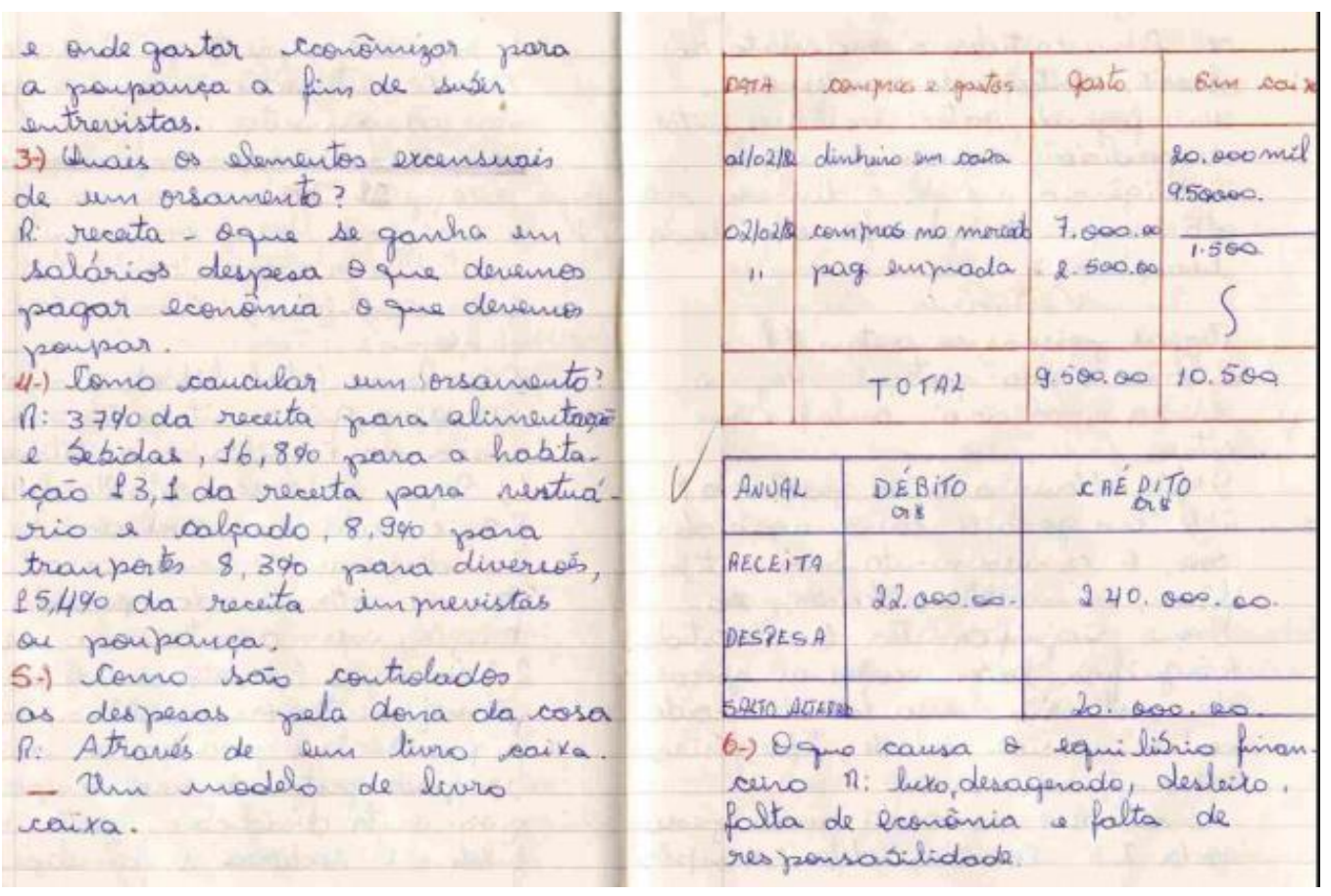

Figura 01: Livro Caixa. Caderno de Indústria Caseira, 1982, p. 38-39.

Acervo pessoal da estudante.

Com a sistematização de todos os possíveis gastos familiares, a figura 01 , referente aos registros de Liza sobre o controle dos gastos, a disciplina de Indústria Caseira desenvolveu noções de economia doméstica. No que corresponde ao conteúdo dos manuscritos, para racionalizar os gastos 


\section{Revista Ibero-Americana de Humanidades, Ciências e Educação \\ Produção e democratização do conhecimento na Ibero-América}

familiares, as estudantes foram instruídas de como programar e controlar as finanças. Alimentação, bebidas, roupas, transportes, e até mesmo diversões. Conforme a composição da disciplina, com a assimilação desses ensinamentos e de maneira controlada proporcionariam o bem estar da família. Uma programação bem elaborada da utilização do dinheiro feita pelas esposas onde deveria ainda prever uma poupança e evitar gastos imprevistos, pois a renda familiar era gerada pelo homem e não caberia a mulher desfrutar do dinheiro para interesse próprio. Uma extensão dos ensinamentos de como as famílias deveriam organizar-se e que estavam respaldadas pelo meio jurídico. Coelho e Puga, ao analisarem o artigo 233 do código civil de 1916, nos informam que, "quando a mulher na sociedade conjugal é declarada apenas como uma colaboradora e, inclusive, neste pacto social perde o direito até de administrar os seus bens particulares que porventura houver." (COELHO; PUGA, 2009, p. 13) Como maneira de obter o controle sobre o destino do dinheiro, a professora ensina às estudantes a necessidade de ter um livro caixa, para anotar todas as entradas e saídas. Liza escreve em seu caderno uma tabela representando o referido livro, apontando exemplos como o salário, gastos no mercado e com o pagamento de uma possível empregada. Por meio dessa observação, importante compreender a classe como outro marcador social presente nesse processo de ensino. A disciplina foi desenvolvida em uma escola pública. Independente das condições econômicas de Liza, esse conteúdo permite perceber que as condições econômicas deveriam usufruir de um estilo de vida que necessita de condições econômicas favoráveis a manter a diversidade de produtos e consumo dentro do lar, assim como ter alguém - uma mulher- a disposição para realizar os trabalhos domésticos. Logo, esse ensinamento reforça diferenças de gênero e classe, mas ao mesmo tempo age para as estudantes menos favorecidas economicamente como uma das possibilidades de aprender a gerir a pobreza.

Importante destacar que essa educação era endereçada a estudantes do gênero feminino da turma de $7^{a}$ série. Com base na idade escolar prevista em lei, a obrigatoriedade da entrada das crianças aos 7 anos nos bancos escolares faria 


\section{Revista Ibero-Americana de Humanidades, Ciências e Educação \\ Produção e democratização do conhecimento na Ibero-América}

com que aos 11 anos de idade marcasse a entrada na pré- adolescência período que vai até os 14 anos - e sem reprovação atingissem o ensino fundamental II correspondente a $5^{\mathrm{a}}$ a $8^{\mathrm{a}}$ séries. Sendo o ensino desta fase direcionado a instrução técnica, compreende-se que durante o período estudado priorizava-se que desde muito cedo que as crianças começassem a trabalhar. Contudo, em meio a precariedade existente as leis trabalhistas não garantiam a seguridade dos menores de idade. Como destaca Sílvia Maria Fávero Arend, "o fato de um contingente populacional ingressar no mercado de trabalho formal e informal desde a infância não constituía uma questão que devesse ser tratada no âmbito da legislação para o "menor"." (AREND, 2015, p.42).

Tal posição compartilhada na educação desenvolvida na escola coaduna com o posicionamento de Katya Mitsuko Braghini. Segundo a autora, entre as décadas de 1960 a 1980, de uma forma bastante intensa a educação desenvolvida no Brasil priorizou a construção de uma juventude trabalhadora. Com base nas reflexões de Braghini e as propostas desenvolvidas por intermédio da disciplina de "Indústria Caseira", no que corresponde ao trabalho e a escola tais ensinamentos endereçaram-se de forma distinta principalmente para as diferenças de gênero, os/as estudantes enquanto estivessem no ensino fundamental II em um período que não poderiam ainda ser definidos/as como jovens, informou por meio dessa disciplina a noção de que as meninas estavam "entrando na juventude" e deveriam pensar sobre o casamento. Já em relação ao trabalho, a LDBde 1971 informou como o período escolar como momento de receber a instrução adequada para garantir resultados positivos no futuro. Como lembra Braghini, nesse período "a escola, mais do que a família, deveria ter propriedade da distribuição de futuros possíveis." (BRAGHINI, 2015, p. 211) No que compete a Liza, sua idade não correspondia ao preceitos estabelecidos pela legislação, pois com 15 anos na sétima série já ultrapassava os interesses de que os/as estudantes devessem concluir o ensino fundamental aos 14 anos.

Ainda sobre os gastos, consta no caderno: "[...] como controlar o orsamento [sic] do lar R: controlando as despesas, não fazendo gastos inúteis, 


\section{Revista Ibero-Americana de Humanidades, Ciências e Educação \\ Produção e democratização do conhecimento na Ibero-América}

evitar desperdícios, economizar com inteligência, e se [sic] o dinheiro não é o suficiente planejar atividades lucrativas." (INDÚSTRIA CASEIRA, 1982) Ou seja, administrar o lar é muito mais que limpar e cozinhar, por isso as futuras donas de casa precisavam ter o domínio sobre assuntos financeiros. Até a década de 1960, o lar deveria representar o poder aquisitivo da família, como uma marca de sucesso e poder dos homens; conforme Carla Pinsky, "[...] a esposa economicamente dependente e satisfeita com o que lhe é dado para as despesas pessoais e domésticas." (PINSKY, 2012, p. 506) O controle das finanças da família, ao menos nos conteúdos da disciplina de Indústria Caseira, haviam sido ressignificados para um período compreendido como moderno mas que permanecia a insistência em restringir a participação das mulheres apenas no âmbito doméstico. E quando a extrema necessidade de trabalhar fora de casa, a extensão dessas atividades como trabalhadora doméstica. Cabe destacar que por meio dos escritos do caderno de "Indústria Caseira", a atuação da escola disciplina - vai além da imposição de modalidade de escrita. Apresenta as estudantes modelos de como trabalhar, vestir-se, casar, alimentar-se, dentre outras imposições pautadas em normativas heterossexuais, étnicas, classe, geração, onde por meio da distribuição dos conteúdos torna-se possível também perceber a hierarquia presente nos "temas" a serem aprendidos.

Para tanto, essas representações sobre as meninas/mulheres correspondem a tentativas de projetar o futuro das estudantes e de um modo bastante explicito reforçar as diferenças entre homens e mulheres geração, etnia e classe. Uma forma de manter a estabilidade e continuidade entre relações sociais desiguais. Materializado em meio aos manuscritos, Liza demostra os significados impostos tanto pela escrita como em relação ao conteúdo onde são possíveis de compreender parte das ideias e pensamento da sociedade, entre eles o que é ser jovem. Ao preencher o caderno, Liza perenizou por meio de sua escrita a concepção de mulher que parte de Guarapuava tinha no ano de 1982. Nessa educação, gênero, etnia, geração e classe estão entrelaçados para as definições do que é ser jovem. Como apresentado, a educação recebida na escola contribuiu para reforçar diferenças instituídas pautadas na 


\section{Revista Ibero-Americana de Humanidades, Ciências e Educação \\ Produção e democratização do conhecimento na Ibero-América}

heteronormatividade onde nos informa que as estudantes do gênero feminino sairiam da escola preparadas para o casamento. Uma construção social onde a maternidade e casamento são vistas como correspondentes a juventude das mulheres. Logo, a juventude como período de escolhas, formação acadêmica e demais atividades que possam ter maior liberdade Ihes são negadas pela cobrança da maturidade em casar-se e ter filhos (homens). Cobranças diferentes das dos homens, onde a juventude deles é vista como promissora e independente. Diante desse ensino, essas expectativas são construídas de forma a instruir como as estudantes deveriam representar-se socialmente no futuro. O conteúdo do caderno serve como um lembrete para de como realizar as tarefas e ser a mulher que idealizada no ensino escolar recebido. Ter arquivado o caderno 36 anos após ter frequentado a disciplina demostra importância atribuída aos manuscritos. Onde tanto pelos efeitos dos ensinamentos da disciplina, produção da escrita do caderno, aos 51 anos de idade Liza continua a integrar as relações sociais da atualidade onde o horizonte de expectativa move-se no presente. Uma história em movimento que como nos lembra Henry Rousso, "a particularidade da história do tempo presente está em que ela se interessa por um presente que é o seu, em um contexto em que o passado não está nem acabado, nem encerrado, em que o sujeito da narração é um "ainda- aí." (ROUSSO, 2016, p. 18).

\section{Referências}

AREND, Silvia Maria Fávero. Convenção sobre os Direitos da Criança: em debate o labor infantojuvenil (1978 - 1989). Revista Tempo e Argumento, Florianópolis, v. 7, n.14, p. 29 - 47.jan./abr. 2015.

BRAGHINI, Katya Mitsuko Zuquim. Juventude e pensamento conservador no Brasil. São Paulo; Educ: Fapesp, 2015.

CASTILLO GÓMEZ, Antonio. Educação e Cultura Escrita: a propósito dos cadernos e escritos escolares. Educação- PUCRS, Porto Alegre, v. 35, n. 1, p. 66-72, jan./abr. 2012. Disponível em: http://revistaseletronicas.pucrs.br/ojs/index.php/faced/article/view/10366 Acesso em 08 de maio de 2018.

Grafias do cotidiano. Escrita e sociedade na História (séc XVI a 


\section{Revista Ibero-Americana de Humanidades, Ciências e Educação \\ Produção e democratização do conhecimento na Ibero-América}

$X X)$. (2018). Rio de Janeiro:Editora da UERJ.(no prelo)

CHARTIER, Roger. A história ou a leitura do tempo. Belo Horizonte: Autêntica Editora, 2010.

COELHO, Castro e Coelho; PUGA, Vera Lucia. Direitos dos homens e deveres das mulheres.Caderno Espaço Feminino v. $22 \mathrm{n} .2$

Ago./Dez. 2009 Disponível em:

http://www.seer.ufu.br/index.php/neguem/article/view/7991 Acesso em 18 de maio de 2019.

DOSSE, François. O renascimento do acontecimento: Um desafio para 0 historiador: entre Esfinge e fênix. São Paulo, Editora UNESP, 2013.

- História do Tempo Presente e Historiografia. Tempo e

Argumento, Florianópolis, v.4, n.1, p.5-22, jan./jun. 2012.

Disponível em:

http://revistas.udesc.br/index.php/tempo/article/view/2175180304012012005

Acesso em 01 de maio de 2019.

FÁVERI, Marlene; TANAKA, Teresa Adami. Divorciados, na forma da lei: discursos jurídicos nas ações judiciais de divórcio em Florianópolis (1977 a 1985). Revista Estudos Feministas, Florianópolis, 18(2): 352, maio-agosto, 2010.

GROPPO, Luís Antonio. Introdução á sociologia da juventude. Jundiaí: Paco Editorial, 2017.

KOSELLECK, Reinhart. Estratos do tempo: estudos sobre História. Rio de Janeiro: Contraponto: PUC-Rio, 2014.

NICHNIG, Claudia Regina. Mulher, Mulheres, Mulherio: discursos, resistências e reinvindicações por direitos. Rio de Janeiro: Editora Multifoco, 2013.

PISCITELLI. Adriana. Interseccionalidades, categorias de articulação e experiências de migrantes brasileiras. Sociedade e Cultura, v.11, n.2, jul/dez. 2008. p. $263 \quad$ a $274 . \quad$ Disponível em: https://www.revistas.ufg.br/fchf/article/view/5247/0 Acesso em 18 de maio de 2019.

PINSKY, Carla Bassanezi. A era dos modelos rígidos. In: PINSKY, Carla Bassanezi; PEDRO, Joana Maria. (Orgs.). Nova história das mulheres no Brasil. São Paulo: Contexto, 2012, p. 469-512.

ROUSSO, Henry. A última catástrofe: a história, o presente, o contemporâneo. Rio de Janeiro: Ed. da FGV, 2016. 